Article

\title{
Fatigue and Fracture Resistance of Heavy-Section Ferritic Ductile Cast Iron
}

\author{
Matteo Benedetti ${ }^{1}{ }^{*}$, Elisa Torresani ${ }^{1}$, Vigilio Fontanari ${ }^{1}$ and Danilo Lusuardi ${ }^{2}$ \\ 1 Department of Industrial Engineering, University of Trento, 38122 Trento, Italy; \\ elisa.torresani@unitn.it (E.T.); vigilio.fontanari@unitn.it (V.F.) \\ 2 Fonderie Ariotti S.p.A., 25030 Adro BS, Italy; danilo.lusuardi@fondariotti.it \\ * Correspondence: matteo.benedetti@unitn.it; Tel.: +39-0461-282-457; Fax: +39-0461-281-977
}

Academic Editor: Filippo Berto

Received: 15 February 2017; Accepted: 6 March 2017; Published: 10 March 2017

\begin{abstract}
In this paper, we explore the effect of a long solidification time (12 h) on the mechanical properties of an EN-GJS-400-type ferritic ductile cast iron (DCI). For this purpose, static tensile, rotating bending fatigue, fatigue crack growth and fracture toughness tests are carried out on specimens extracted from the same casting. The obtained results are compared with those of similar materials published in the technical literature. Moreover, the discussion is complemented with metallurgical and fractographic analyses. It has been found that the long solidification time, representative of conditions arising in heavy-section castings, leads to an overgrowth of the graphite nodules and a partial degeneration into chunky graphite. With respect to minimum values prescribed for thick-walled $(t>60 \mathrm{~mm}$ ) EN-GJS-400-15, the reduction in tensile strength and total elongation is equal to $20 \%$ and $75 \%$, respectively. The rotating bending fatigue limit is reduced by $30 \%$ with respect to the standard EN-1563, reporting the results of fatigue tests employing laboratory samples extracted from thin-walled castings. Conversely, the resistance to fatigue crack growth is even superior and the fracture toughness comparable to that of conventional DCI.
\end{abstract}

Keywords: heavy-section ductile cast iron; chunky graphite; fatigue limit; fatigue crack growth resistance; fracture toughness

\section{Introduction}

Low production cost and excellent castability make ductile cast iron (DCI) the preferred material choice when low-to-moderately stressed mechanical components of complicated shape and large dimensions must be manufactured. It is used in many applications where strength and toughness are required, such as automotive parts, windmill parts, pipes, etc. The microstructural control of DCI is of paramount importance as it greatly influences a wide range of mechanical properties. The typical microstructure consists of graphite nodules dispersed in a matrix that can be ferritic, ferritic and/or pearlitic depending on the alloy formulation, the casting control and the final heat treatment [1,2]. The ferritic matrix displays usually the lower tensile and fatigue strength but also a noticeable ductility, which have promoted the DCI in the production of thick walled parts undergoing in service low/medium levels of mechanical stresses.

Casting large volume parts of weight on the order of tens of tons is particularly critical as the control of the final microstructure is rather difficult [3-5]. Consequently, solidification defects cannot be completely avoided, their presence must be somehow tolerated and different strategies are pursued to limit their detrimental effects. Typical design approaches are either to force the localization of the heterogeneous microstructure in regions undergoing very low "in service" stress levels or in regions that are removed during finishing operations. The choice is strongly connected to the knowledge of the detrimental effects of the microstructural defects on the mechanical behavior, specifically ductility and 
fatigue behavior [3]. The fatigue performance of DCI with different microstructures is widely analyzed in the technical literature [2-9]. Notably, Meneghetti et al. [6] showed the results of an extensive experimental study comparing different microstructures in a large range of fatigue lives. It can be observed that quite often, in research papers, fatigue tests are carried out on specimens taken from the Y-block or from small laboratory casting batches, thus accounting only partially for the heterogeneous microstructure arising in real parts. In fact, the final microstructure can be efficiently controlled in small materials batches, whereas, in real part, especially thick-walled components [3,4], some intrinsic defects are unavoidable. The difficult control of the casting process introduces into the material intrinsic defects, such as solidification cavities or poor graphite nodularity, dross and degenerated (chunky and spiky) graphite, which can be tolerated up to a certain level. Many works [1,3-5,7,10-12] found that these defects are preferential fatigue crack initiation sites; therefore, their distribution and the morphology are of particular importance when designing against fatigue. The results of laboratory tests are very useful for defining the role of the graphite morphology in the propagation of fatigue cracks through the specimen cross section [2,9-13]. In addition, the size and uniformity of distribution of graphite nodules can affect the properties of DCI, but with a lower effectiveness than graphite shape [14]. Indeed, graphite spheroids act like "crack-arresters" promoting the mechanical properties of the matrix; on the contrary, the presence of irregular shapes or non-spheroidal graphite such as chunky, exploded, spiky, vermicular and intercellular flake graphite worsens the mechanical properties. All these degenerated graphite morphologies are usually present in thick-walled components. The main factors that influence the degeneration of the graphite are the chemical composition and the cooling rate, especially in the case of the chunky graphite, which is the most frequent defect in heavy sections and is mainly observed in the thermal core [15-19]. In the technical literature, various theories have been proposed to explain the metallurgical processes responsible for the formation of chunky graphite [20-24] but none have received unanimous agreement. Nevertheless, it is well known that the chunky graphite is favored by high concentration of $\mathrm{Si}, \mathrm{Ni}, \mathrm{Ca}$ and carbon equivalent elements [25-27]. Small amounts of rare earth elements such as $\mathrm{Ce}, \mathrm{Nd}, \mathrm{Pr}, \mathrm{Sm}$ and $\mathrm{Gd}$ induce graphite spheroidization [28-30]; however, if their concentration becomes excessive, they provoke the formation of chunky graphite due to the segregation at austenite grain boundaries $[28,29]$. The graphite morphology is influenced by another important factor that is also difficult to control in heavy-section castings, viz. the cooling rate [31-33]. Fast cooling allows a quick enveloping of graphite nodules by a shell composed of several austenite grains [34]. This helps to maintain the spheroidal graphite shape. The formation of the austenitic shell is delayed at low cooling rates. In this situation, liquid channels separate the austenitic grains and allow a longer contact time of the spherical graphite with the melt. Through these channels, carbon atoms diffuse towards the spheroidal graphite, causing their growth and degeneration [35]. Low-melting elements such as $\mathrm{Al}, \mathrm{Sn}$, and $\mathrm{Pb}$ tend to segregate thus delaying the formation of the austenite shell [34]. A similar effect is shown by segregating elements such as Mn, Mo, Cr, W, V and $\mathrm{Ti}$, which are concentrated in the liquid channels [34]. A proper inoculation is an important factor to improve the nucleation factor of the melt, increase the nodularity and nodule count and reduce the carbides formation [36]. On the other hand, melt inoculation induces an increasing risk of chunky graphite formation in thick-walled components [37].

The mechanical properties are influenced by microstructure and solidification defects, and specifically the increase in non-nodular graphite content decreases the mechanical strength; indeed, the ultimate tensile strength and mostly the elongation to fracture are severely lowered, despite hardness and yield strength remain nearly unaffected [38,39]. Regarding the effect of the chunky graphite on the fatigue performance, different works have been published [11,40-42]. Mourujärvi et al. [40] analyzed the performance of a normalized DCI EN-GJS-800 containing different quantities of chunky graphite through rotating bending fatigue tests. They showed that the increase of chunky content up to $20 \%$ and more induces a significant decrease in fatigue lifetime, with a drop of fatigue limit on the order of $30 \%-40 \%$. In another study [41], uniaxial pulsating fatigue tests were performed on ferritic DCI containing $40 \%$ of chunky graphite. In this case, a quite limited decrease in fatigue resistance is attained, 
with a reduction of fatigue limit of only $14 \%$, whose main cause has been attributed to the presence of microporosities. Indeed, different works [43-45] showed that the fatigue limit is much more sensitive to surface defects than internal defects, where it is observed that micro-shrinkage cavities strongly influence the fatigue behavior of DCI castings. Foglio et al. [42] conducted fatigue tests on two different EN-GJS-400 DCI, in one of which the chunky graphite formation was induced by adding Ce-containing inoculants. Using a statistic analysis and applying the Murakami equation [39,46] to correct for the contribution of microporosity on the fatigue strength reduction, they estimated a decrease in the fatigue limit due to chunky graphite of $12 \%$, which reflects a comparable drop in tensile strength equal to $14 \%$.

From the above discussion, it is clear that the effect of chunky graphite on static and cyclic properties has been largely investigated in the literature. However, the design of high-added value components of large dimensions, such as those employed in MW-series wind turbines [47], cannot rely on the knowledge of these mechanical properties only. In fact, infinite life design approaches usually take large safety margins thus resulting in very heavy constructions, while safe life approaches suffer from large uncertainty on the actual lifetime of the component prior to its withdrawal from service. Damage tolerant design and structural health monitoring approaches have been then proposed to overcome these limitations. They were originally developed in the aeronautic context and have now been extended to the wind energy branch, especially in offshore and hardly-accessible installations [48,49]. According to these approaches, the fatigue life is exclusively thought of as the propagation of cracks up to a critical size leading to structural collapse or functionality loss. Therefore, they require a detailed characterization of the fracture toughness and the fatigue crack growth resistance of the castings in order to assess the critical crack size and the time to propagation to this critical value. In the present paper, we address this latter issue by investigating the crack growth resistance of a DCI produced under very slow cooling conditions, thus representative of the microstructural conditions arising in thick walled castings. For this purpose, static tensile, fatigue and fracture mechanics tests are performed to quantify the resistance to fatigue crack initiation and propagation as well as the fracture toughness. The paper is organized as follows. Section 2 describes the casting procedure followed to obtain a microstructure with degenerated chunky graphite and the experimental methods adopted for determining the mechanical properties. Section 3 illustrates the experimental results and discusses them on the basis of comparisons with literature data. The conclusions close the paper.

\section{Material and Experimental Procedures}

The experimentation is performed on an EN-GJS-400-type ferritic DCI, whose chemical composition is listed in Table 1. Small-scale castings are obtained from an innovative production line described in [50] and designed to reproduce the solidification conditions of heavy-section castings (with masses of tens of tons). It consists of an electric furnace where the solidification of a cylinder with $240 \mathrm{~mm}$ diameter and $260 \mathrm{~mm}$ height (about $80 \mathrm{~kg}$ mass) takes place under controlled conditions. The mold is made up of a special alumina-based refractory crucible, suitably designed to contain the liquid cast iron and to be handled with cast iron inside. The crucible is preheated at $1200{ }^{\circ} \mathrm{C}$ in the electric furnace, and then it is removed from the furnace and filled with the cast iron at $1350-1370{ }^{\circ} \mathrm{C}$. The crucible is covered with a kerphalite lid and placed back into the furnace, setting the power control of the furnace to the desired solidification time. The furnace is maintained under inert Ar atmosphere to avoid melt exposure to oxygen. The cooling phase is monitored using a thermocouple inserted into the casting through the lid, and the cooling curve, shown in Figure 1, is recorded by means of a data logger with $30 \mathrm{~s}$ sampling time. It can be noted that the solidification time is about $12 \mathrm{~h}$ and that the eutectic phase transformation takes approximately $10 \mathrm{~h}$. A specific testing campaign conducted in [50] on coupons extracted from both heavy-section and small-scale castings demonstrated the capability of the present experimental method to produce very similar microstructural conditions. 
Table 1. Chemical composition of the investigated ferritic ductile cast iron (wt \%), balance Fe.

\begin{tabular}{ccccccccc}
\hline $\mathbf{C}$ & $\mathbf{S i}$ & $\mathbf{M n}$ & $\mathbf{C u}$ & $\mathbf{S n}$ & $\mathbf{S}$ & $\mathbf{M g}$ & $\mathbf{C r}$ & $\mathbf{P}$ \\
\hline 3.59 & 2.51 & 0.23 & 0.11 & 0.0031 & 0.0109 & 0.0462 & 0.043 & 0.044 \\
\hline
\end{tabular}

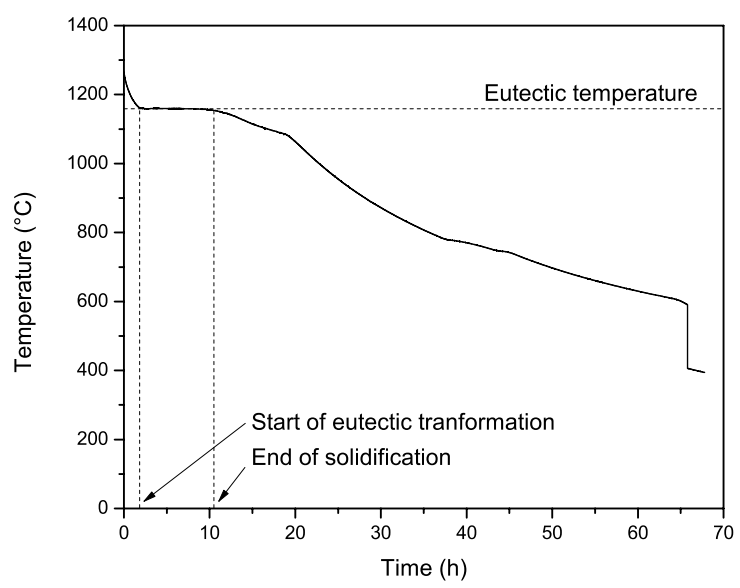

Figure 1. Record of the temperature measured by a thermocouple inserted into the casting during the solidification phase.

The microstructure is characterized by conventional metallographic analyses. Samples are mounted and ground from 220 to 4000 mesh $\mathrm{SiC}$ abrasive papers. The final polishing is done using a 3-micron diamond paste followed by a 0.04-micron alumina suspension. Nital etching is used to reveal the microstructure. Quantitative analysis is conducted using image analysis software Image ${ }^{\circledR}$.

Monotonic tensile tests are performed according to the standard UNI EN ISO 6892-1 on dog-bone coupons (14 mm gauge diameter, $84 \mathrm{~mm}$ parallel length), shown in Figure 2a, using a servo-hydraulic universal testing machine, equipped with hydraulic grips, a load cell of $200 \mathrm{kN}$. The yield strength is determined as the $0.2 \%$ offset yield stress.

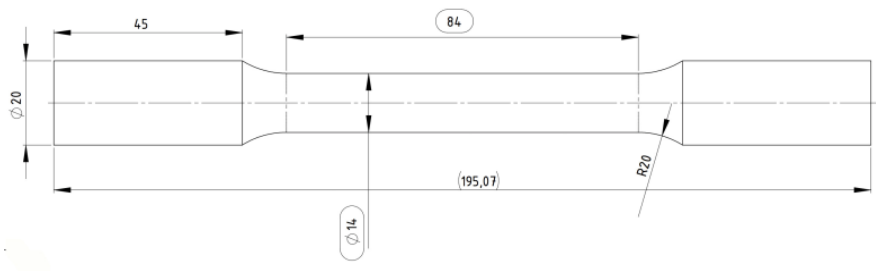

(a)

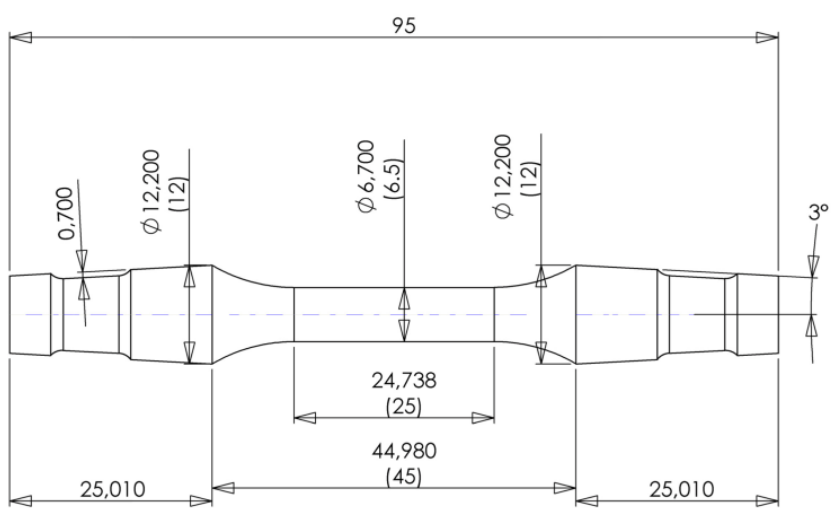

(b)

Figure 2. Cont. 


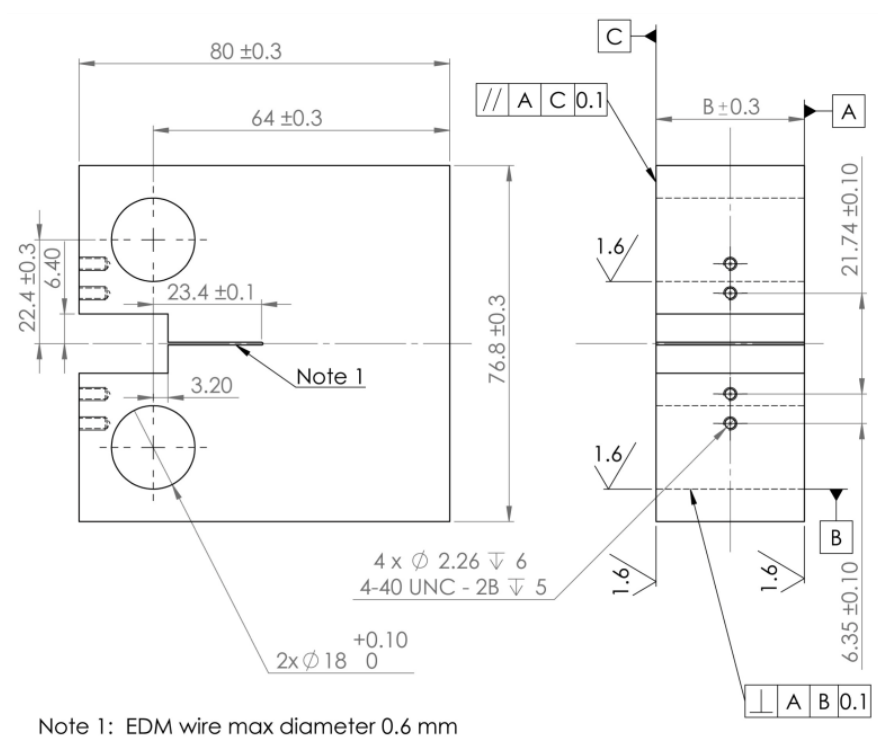

(c)

Figure 2. Geometry of the specimens used in the present experimentation. (a) Dog-bone samples used for monotonic tensile tests; (b) Uniform-gage test section samples used in rotating bending fatigue tests; (c) Compact tension C(T) specimens used in fracture mechanics tests. Dimensions are given in $\mathrm{mm}$. The thickness $B$ of the $\mathrm{C}(\mathrm{T})$ specimens is equal to $10 \mathrm{~mm}$ and to $32 \mathrm{~mm}$ for fatigue crack growth rate and fracture toughness tests, respectively.

Brinell hardness is measured by using a B3000 J hardness tester (Mechatronic Control System, Ichalkaranji, India) equipped with a $10 \mathrm{~mm}$ diameter sphere and applying a load of $29.4 \mathrm{kN}$. For each sample, at least three measurements are performed and the average value is calculated.

Fatigue tests are performed on hourglass specimens depicted in Figure $2 b$ according to the standard ASTM E466. Rotating bending fatigue tests (load ratio $R=-1$ ) are carried out under load-control at a nominal frequency of $100 \mathrm{~Hz}$ in laboratory environment $\left(25^{\circ} \mathrm{C}, 60 \%\right.$ R.H.). The fatigue strength corresponding to a fatigue life of $5 \times 10^{6}$ cycles is obtained by a staircase procedure, employing 15 samples and $10 \mathrm{MPa}$ stress increments. Fatigue fracture surfaces have been investigated using a JEOL (Japan Electron Optics Laboratory Company, Ltd., Akashima, Japan) JSM-IT300LV scanning electron microscope (SEM) (Japan Electron Optics Laboratory Company, Ltd., Akashima, Japan) equipped with an EDXS probe for quantitative chemical analysis.

The fracture mechanics tests are carried out on compact $\mathrm{C}(\mathrm{T})$ specimens whose geometry, compliant with the standard ASTM E1820-09, is illustrated in Figure 2c. Specifically, $\mathrm{K}_{\mathrm{Ic}}$ fracture toughness and fatigue crack growth rate tests are performed on 32 and $10 \mathrm{~mm}$ thick specimens, respectively. The initial notch of all C(T) specimens is Electro Discharge Machined (EDM) with a wire of $0.5 \mathrm{~mm}$ diameter to facilitate the follow-up pre-cracking process.

The fatigue crack growth rate testing is performed according to the standard ASTM E647-08. The experiments are conducted in the laboratory environment on a resonant testing machine Rumul (Russenberger Prüfmaschinen, AG, Neuhausen am Rheinfall, Switzerland) Testronic 50 kN. A sinusoidal pulsating load waveform is applied at a frequency of $\sim 100 \mathrm{~Hz}$. Tests are performed at three load ratios $R$, namely $0.1,0.5$ and 0.75 . A Fractomat ${ }^{\circledR}$ (Augustine, FL, USA) apparatus based on the indirect potential drop method is used to continuously measure the crack length. For this purpose, a crack length foil (Krak gage ${ }^{\circledR}$ (Augustine, FL, USA)), consisting of a conducting layer on an electrically insulating backing, is bonded on one side of the $C(T)$ sample and then connected to a signal conditioning module, whose output can be used to feed-back control the testing machine. Periodically, the crack length on the back face of the sample is inspected using a travelling microscope to make sure that the two crack lengths do not differ by more than 0.25 times the sample thickness, 
as prescribed by the standard ASTM E647-08. The crack growth rates are calculated from discrete crack length increments of $0.3 \mathrm{~mm}$, necessary for sampling the fatigue crack growth resistance of the fairly coarse material microstructure. The tests are performed in two distinct phases. In the initial force-shedding phase, the applied $\Delta K$ is exponentially reduced by setting the decay constant $C=-\frac{1}{K} \frac{\mathrm{d} K}{\mathrm{~d} a}=0.08 \mathrm{~mm}^{-1}$ until reaching near-threshold fatigue crack growth conditions. A specific testing campaign, further described in the following, has been carried out to identify the minimum crack size requested to fully develop the extrinsic crack growth resistance mechanisms of the material, which greatly influence the fatigue crack growth threshold. The final part of the experiments is performed under constant force amplitude and the crack growth rate data are used to build the $\mathrm{d} a / \mathrm{d} N$ vs $\Delta K$ curves. After the fatigue tests, the specimens are sectioned across the thickness and metallographic samples are extracted in order to investigate the crack front profile. Fracture surfaces are investigated using a JEOL JSM-IT300LV SEM.

Specimens for fracture toughness tests are fatigue precracked to a crack-length-to-specimen-width of about 0.5 using the same resonant testing machine in laboratory environment under $K$-controlled conditions (load ratio $R=0.1$ ) suitable to maintain the crack growth rate below $10^{-8} \mathrm{~m} /$ cycle. After precracking, to enforce the plane strain condition, $20 \%$ V-notch side grooves are machined on the samples, resulting in a net thickness $\left(B_{N}\right)$ of $25.6 \mathrm{~mm}$. Subsequently, the samples are monotonically loaded up to fracture to determine the $K_{\mathrm{c}}$ fracture toughness $\left(\mathrm{d} K / \mathrm{d} t=1 \mathrm{MPa} \sqrt{ } \mathrm{m} \cdot \mathrm{s}^{-1}\right.$, room temperature air) using a $100 \mathrm{kN}$ servo-hydraulic testing machine equipped with a clip-gauge mounted on knife edges attached to the specimen to measure the crack mouth opening displacement. All data of load versus clip gauge displacement are acquired with a sampling rate of $50 \mathrm{~Hz}$. After fracture, the crack length prior to final monotonic loading is measured using an optical microscope following the ASTM E1820-09 standard procedure.

\section{Results and Discussion}

\subsection{Microstructure}

The optical micrograph shown in Figure 3 illustrates a representative example of the material microstructure. It can be noted that the microstructure is highly inhomogeneous, being composed of a predominantly ferritic matrix in which both spheroidal and chunky graphite domains of different size are unevenly distributed. In some regions, the matrix is even pearlitic (visible in the center of Figure 3). To better characterize type, shape and distribution of the graphite particles, ten cross-sections randomly extracted from the samples are metallographically prepared and statistically analyzed. Specifically, the deviation from the spherical shape is estimated by the shape factor expressed as [47]:

$$
f_{0}=\frac{4 \pi A}{U^{2}}
$$

where $A$ and $U$ are the area and perimeter of the particles, respectively. Clearly, $f_{0}$ becomes 1 for an ideal sphere. Table 2 summarizes the results of the statistical analysis of the graphite morphology. It can be noted that about $1 / 3$ of the graphite has degenerated into chunky graphite and that the remaining fraction of spheroidal graphite has overgrown to very large nodules with a mean diameter of about 300 micron. The shape factor of the spheroidal nodules equal to about 0.5 is pretty low in comparison to data available in the literature for DCI obtained under normal solidification conditions [47]. 


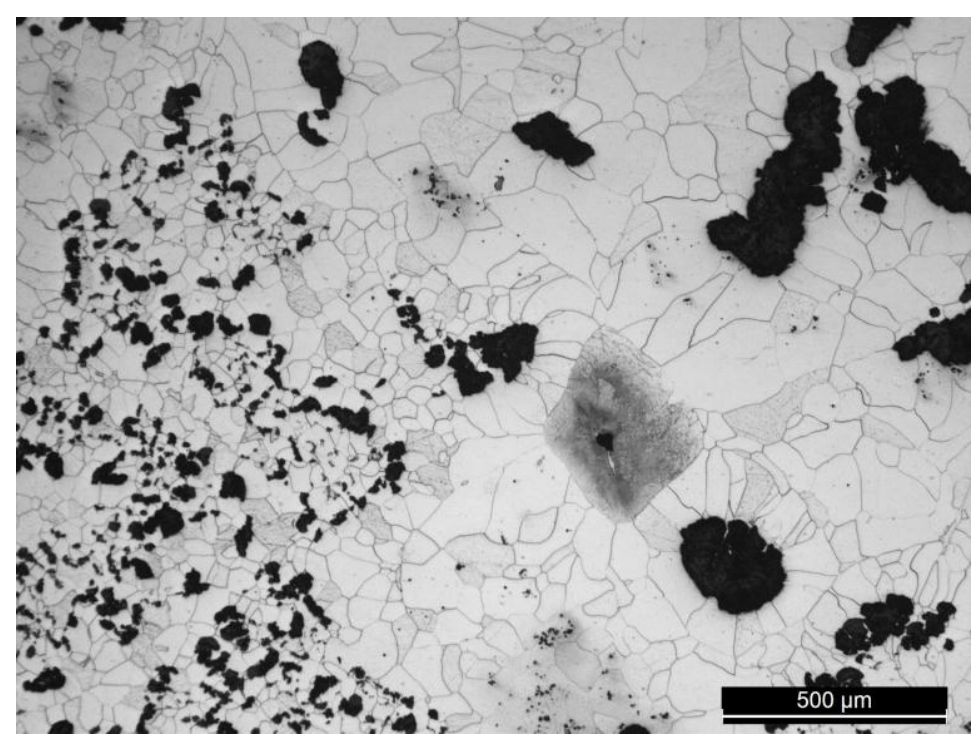

Figure 3. Optical micrograph of the microstructure (etching with $2 \%$ Nital reagent).

Table 2. Results of quantitative analysis done on 10 metallographic samples. Standard error corresponds to $1 \sigma$ uncertainty band.

\begin{tabular}{ccccc}
\hline $\begin{array}{c}\text { Total Graphite } \\
\text { Content (\%) }\end{array}$ & $\begin{array}{c}\text { Fraction of Spheroidal } \\
\text { Graphite (\%) }\end{array}$ & $\begin{array}{c}\text { Fraction of Chunky } \\
\text { Graphite (\%) }\end{array}$ & $\begin{array}{c}\text { Diameter of Spheroidal } \\
\text { Graphite }(\boldsymbol{\mu m})\end{array}$ & $\begin{array}{c}\text { Shape Factor } \\
\text { Spheroidal Graphite } \boldsymbol{f}_{\mathbf{0}}\end{array}$ \\
\hline $9.3 \pm 2.1$ & $71 \pm 15$ & $29 \pm 15$ & $310 \pm 110$ & $0.49 \pm 0.19$ \\
\hline
\end{tabular}

\subsection{Monotonic and High-Cycle Fatigue Properties}

Mean values of materials parameters obtained from the analysis of tensile and hardness data are summarized in Table 3. It can be noted that the very long solidification time and the resulting microstructural alterations lead to low values of tensile strength and total elongation in comparison to conventional ferritic DCI; for instance, with respect to thick-walled ( $t>60 \mathrm{~mm}$ ) EN-GJS-400-15, the reduction in tensile strength and total elongation is about $20 \%$ and $75 \%$, respectively. The yield-stress-to-tensile-strength ratio approaching the unity further denotes a very brittle material behavior, while, as expected, the yield stress is little affected [4], being the yield stress compliant with the minimum prescription of $240 \mathrm{MPa}$ for EN-GJS-400-15.

Table 3. Monotonic tensile (based on four replicated tests) and rotating bending fatigue (from the staircase tests data listed in Table 4) properties of the present material. Standard error corresponds to $1 \sigma$ uncertainty band.

\begin{tabular}{cccccc}
\hline$\sigma_{\mathbf{Y S}}(\mathbf{M P a})$ & $\boldsymbol{\sigma}_{\mathbf{U}}(\mathbf{M P a})$ & $\boldsymbol{\sigma}_{\mathbf{Y S}} / \boldsymbol{\sigma}_{\mathbf{U}}$ & T.E. (\%) & HB & $\boldsymbol{\sigma}_{\text {lim, }-\mathbf{1}}(\mathbf{M P a})$ \\
\hline $275 \pm 4$ & $295 \pm 8$ & 0.93 & $2.9 \pm 0.2$ & $144 \pm 2$ & $138 \pm 4$
\end{tabular}

$\sigma_{Y S}: 0.2 \%$ yield stress; $\sigma_{U}:$ ultimate tensile strength; T.E.: total elongation; HB: Brinell hardness. $\sigma_{\text {lim, }-1}:$ rotating bending fatigue limit at five million cycles.

The results of the rotating bending fatigue tests are summarized in Table 4. The statistical elaboration of the fatigue data according to the staircase procedure leads to estimate the five million cycles fatigue limit (50\% failure probability) equal to $138 \mathrm{MPa}$ with $4 \mathrm{MPa}$ standard deviation. In addition, in this case, it can be noted that the long solidification time leads to low fatigue properties, in fact the fatigue limit is 30\% below the typical value of $195 \mathrm{MPa}$ indicated in the European standard EN-1563 [51] for this DCI class on the base of rotating bending fatigue tests conducted on small-sized $(\phi=10.6 \mathrm{~mm})$ laboratory samples extracted from thin-walled castings $(t \leq 30 \mathrm{~mm})$, thus displaying 
ideal microstructural conditions. Furthermore, the investigations undertaken in [42] on a similar material showed that the presence of 33\% of chunky graphite is responsible for a fatigue limit reduction of $14 \%$. Therefore, it can be inferred that the remaining part of the fatigue limit decrement (about 16\%) observed in the present paper can be imputed to solidification defects induced by the very slow cooling conditions.

Table 4. Results of the rotating bending fatigue tests.

\begin{tabular}{cccc}
\hline Sample Number & Stress Amplitude, $\boldsymbol{\sigma}_{\mathbf{a}} \mathbf{( M P a )}$ & Number of Cycles to Failure, $\boldsymbol{N}_{\boldsymbol{f}}$ & Remarks \\
\hline 5 & 130 & $8,396,603$ & Run-out \\
6 & 140 & $5,181,473$ & Run-out \\
7 & 150 & $3,870,378$ & \\
8 & 140 & $3,535,376$ & Run-out \\
9 & 130 & $8,110,087$ & Run-out \\
10 & 140 & $1,253,313$ & Run-out \\
11 & 130 & $24,732,626$ & Run-out \\
12 & 140 & $2,483,398$ & Run-out \\
13 & 130 & $8,143,060$ & \\
14 & 140 & $1,347,937$ & Run-out \\
16 & 130 & $6,989,257$ & $7,653,654$ \\
17 & 140 & $2,851,237$ & $2,443,680$ \\
20 & 150 & $8,891,424$ & \\
\hline
\end{tabular}

For this purpose, SEM analyses are carried out on the fracture surfaces of the fatigue specimens $\{6,7,8,14,17\}$ to shed light on the damage mechanisms acting in the high-cycle fatigue regime. As shown in Figure $4 a, b$, shrinkage defects are present on the fracture surfaces, usually in regions of nearly complete absence of graphite. They can be either solidification cavities or pores located near the outer surface (Figure 4a) or in the interior (Figure 4b) of the sample, respectively. Kobayashi and Yamabe [5] showed that the presence and the size of these inherent defects control the fatigue limit of ductile cast irons. Specifically, the fatigue limit can be expressed as cyclic threshold stress at which the cracks emanating from the defects do not propagate. This type of analysis can be easily performed with the $\sqrt{\text { area }}$ parameter, defined as the square root of the area obtained by projecting a defect or a crack onto the plane perpendicular to the maximum tensile stress. Accordingly, Murakami and Endo [52] proposed the following equation to predict the fully-reversed fatigue limit $(R=-1)$ :

$$
\sigma_{\text {lim },-1}=\frac{C(H V+120)}{(\sqrt{\text { area }})^{1 / 6}} ; \quad C=\left\{\begin{array}{rr}
1.43 & \text { surface defect } \\
1.56 & \text { internal defect }
\end{array}\right.
$$

where HV is the Vickers hardness.

To check the applicability of this approach to the present material, the area of the largest pore is measured on the fracture surface of each of the above-mentioned samples. The mean and standard deviation of this parameter are estimated to be 164,000 and $78,000 \mu \mathrm{m}^{2}$, respectively. Assuming a Gaussian distribution of these critical defect sizes, the fatigue limit at different failure probabilities can be calculated using Equation (2). Specifically, the fatigue limits corresponding to 50\%, 90\%, and $10 \%$ failure probabilities are estimated to be equal to 149,161 , and $143 \mathrm{MPa}$, respectively, in very good agreement with the experimental values listed in Table 4. 


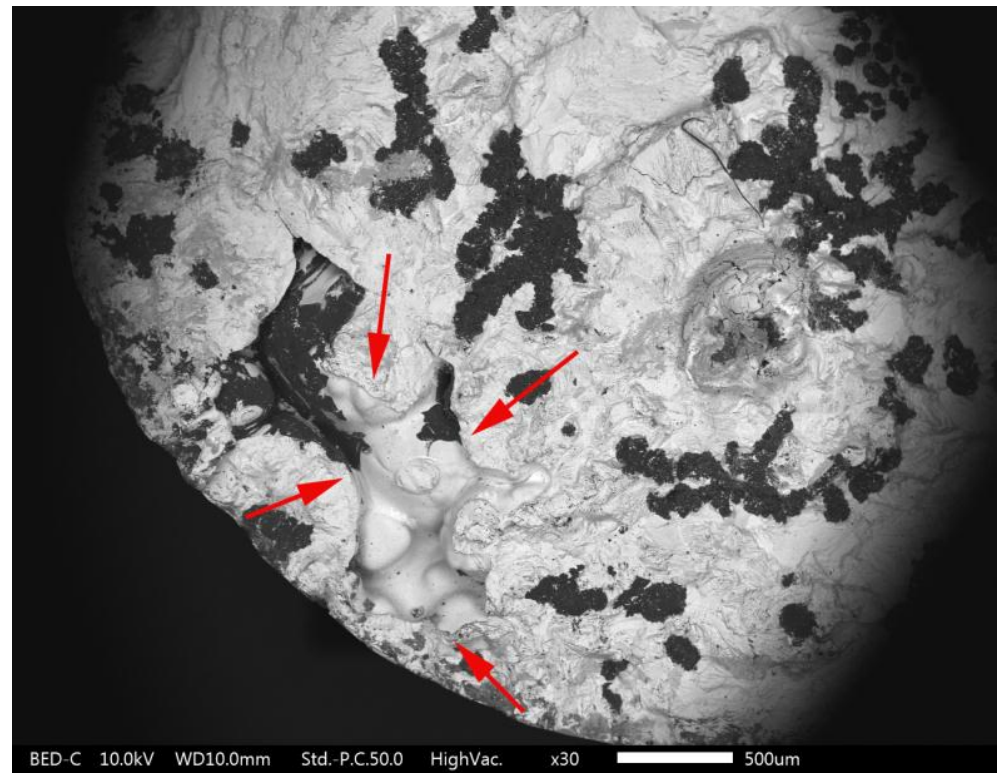

(a)

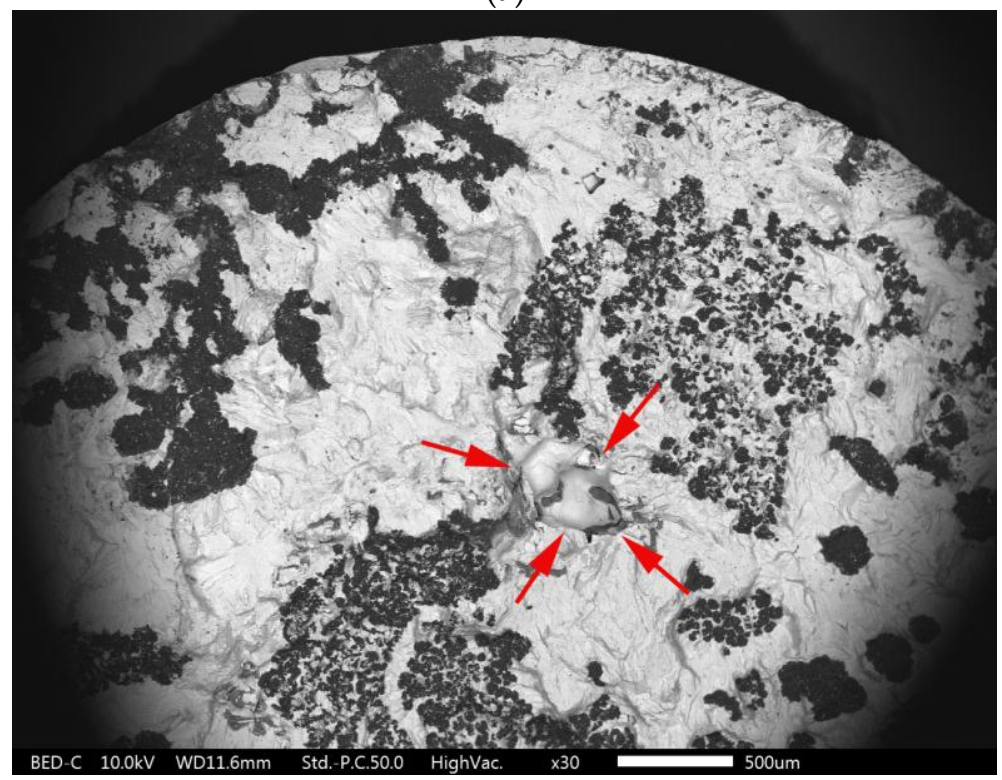

(b)

Figure 4. scanning electron microscope (SEM) micrographs of the fracture surfaces of rotating bending fatigue samples around the largest shrinkage pore marked by red arrows: (a) sample 6 (near-surface cavity); and (b) sample 8 (internal pore). Table 4 indicates stress amplitude and number of cycles to failure.

We must, however, outline that this powerful approach may oversimplify the actual high-cycle fatigue damage mechanism, as shrinkage porosity may not be the only crack nucleation site. To this regard, looking at Figure $4 b$, it can be noted that the pore marked by red arrows is located about $1.7 \mathrm{~mm}$ below the outer surface. It is therefore highly unlikely that this defect, experiencing a bending stress nearly 50\% lower than the highest value achieved on the outer surface, acted as the first crack initiation site. Presumably, other microstructural defects, such as the network of chunky graphite in the vicinity of the pore, are involved in the fatigue damage mechanism and are responsible for the $14 \%$ reduction in fatigue limit estimated in [42]. 


\subsection{Fatigue Crack Growth Curves}

As anticipated in Section 2, fatigue crack growth $\mathrm{d} a / \mathrm{d} N-\Delta K$ curves are measured considering experimental data referring to crack lengths sufficient for the material to fully deploy extrinsic crack growth resistance mechanisms [53,54]. In this way, a more realistic estimation of the actual crack growth resistance in heavy-section castings can be obtained. For this purpose, a specific testing campaign is carried out at $R=0.1$ monitoring the crack growth rate at constant $\Delta K$ and increasing crack length. Representative results are shown in Figure 5. It can be noted that the material exhibits increasing crack growth resistance as the crack extends from the initial EDM crack starter notch of length $a_{0}$. The crack growth resistance tends to saturate when the crack extension is about $4 \mathrm{~mm}$, viz. $40 \%$ of the specimen thickness. This value is considered in the following experimentation as the minimum crack extension for full development of extrinsic crack retardation mechanisms. Indeed, crack tip shielding mechanisms [53], such as crack closure and bridging, acting behind the crack tip, require the crack wake to be sufficiently long to be fully active. They are thus responsible for the development of rising resistance-curve (R-curve) behavior with increasing crack length. It is also known that eliminating by mechanical machining the crack wake behind the crack tip leads to the loss of such mechanisms and to a sudden crack acceleration as long as the crack wake is not fully restored [54]. Therefore, the second phase of crack growth testing performed under constant force amplitude is conducted only after the crack extension has overcome the minimum value of $4 \mathrm{~mm}$. To this regard, it can be noted that Zambrano et al. [55] used C(T) samples with crack sizes less than $2 \mathrm{~mm}$ and reported very low fatigue crack growth resistance in comparison with other papers dealing with similar DCI $[47,56,57]$.

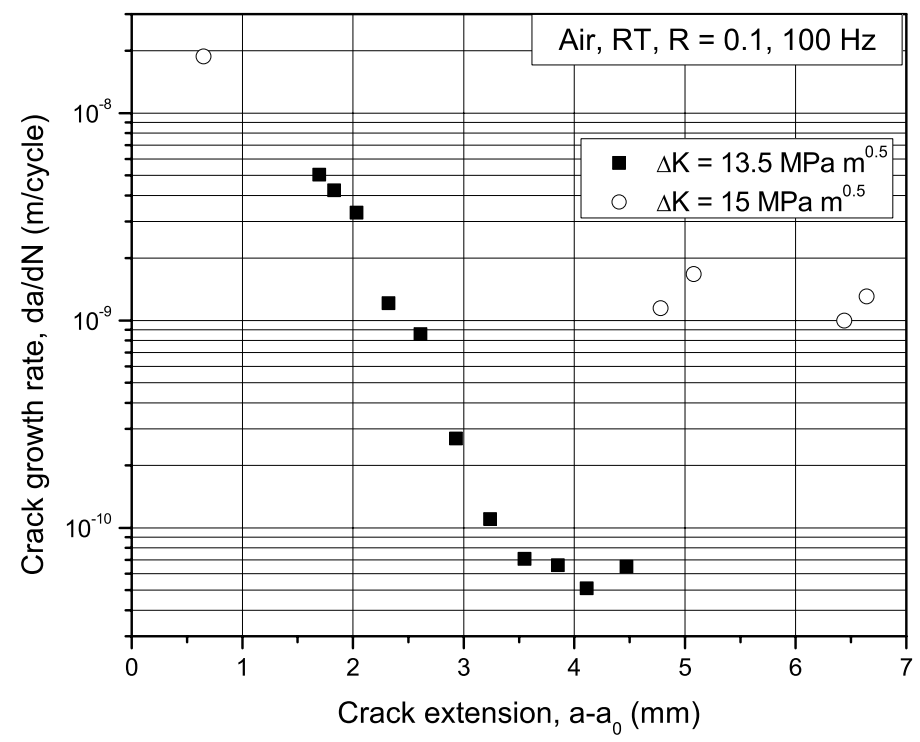

Figure 5. Results of fatigue crack growth tests conducted at constant $\Delta K$ and increasing crack extension from the initial Electro Discharge Machined (EDM) crack starter notch.

The resulting $\mathrm{d} a / \mathrm{d} N-\Delta K$ curves obtained at $R=0.1,0.5$ and 0.75 are compared in Figure 6 . The $R$-ratio effect is evident, indeed the curves move towards higher crack growth rates with increasing $R$, especially in the near-threshold regime. The experimental data are represented by the exponential law proposed by Klesnil and Lukáš [58]:

$$
\frac{\mathrm{d} a}{\mathrm{~d} N}=C\left(\Delta K^{m}-\Delta K_{\mathrm{th}}^{m}\right)
$$

The best-fit parameters are given in Table 5 for the different load ratios used in the tests. It can be noted that Equation (3) well reproduces the material's crack growth behavior in Stages I (near-threshold 
regime) and II (K-controlled regime). When $K_{\max }=\Delta K /(1-R)$ exceeds $\sim 45 \mathrm{MPa} \mathrm{m}^{0.5}$, Stage III crack growth regime commences and $K$-dominance is lost.

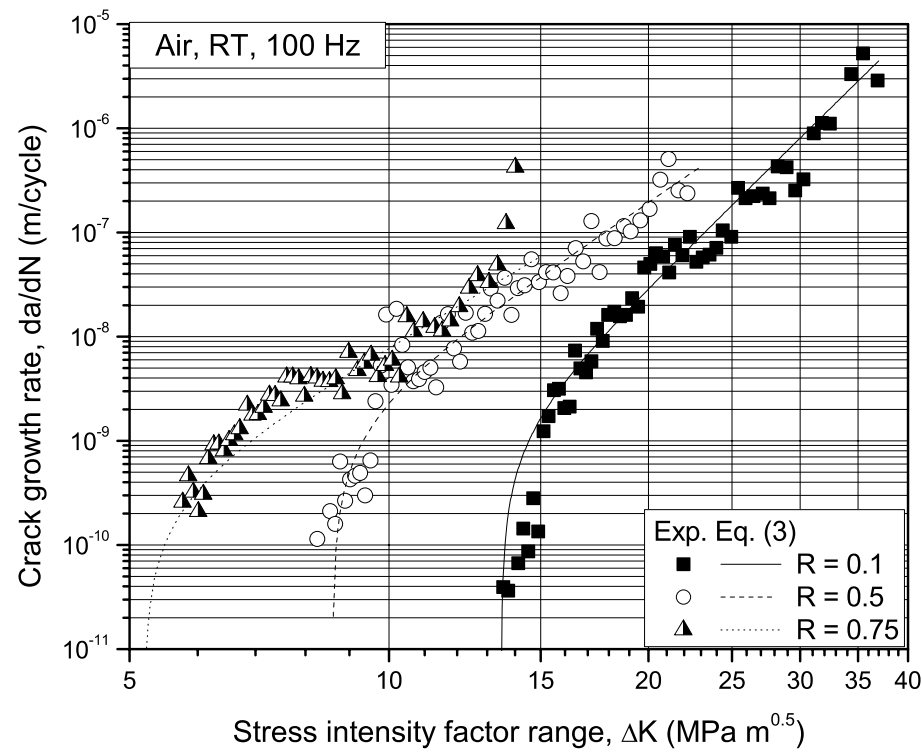

Figure 6. Fatigue crack growth curves plotted as a function of the nominal stress intensity factor range.

Table 5. Best-fit parameters of the crack propagation law expressed by Equation (3).

\begin{tabular}{cccc}
\hline Load Ratio $\boldsymbol{R}$ & $\boldsymbol{\Delta} \boldsymbol{K}_{\text {th }}\left(\mathbf{M P a ~}^{\mathbf{0 . 5}}\right)$ & $\boldsymbol{C}$ & $\boldsymbol{m}$ \\
\hline 0.1 & 13.5 & $7.72 \times 10^{-19}$ & 8.1 \\
0.5 & 8.6 & $9.48 \times 10^{-15}$ & 5.6 \\
0.75 & 5.2 & $9.59 \times 10^{-14}$ & 4.9 \\
\hline
\end{tabular}

Units in Equation (3) are $\mathrm{m} /$ cycle and $\mathrm{MPa} \mathrm{m}^{0.5}$.

Figure 7a compares the curves obtained by fitting Equation (3) to the present experimental data and those measured by Mottitschka et al. [56] on an EN-GJS-400 DCI type with very similar chemical composition but obtained under fast solidification conditions leading to a mean graphite diameter of about $10 \mu \mathrm{m}$ and therefore denoted as G10. Unexpectedly, it can be noted that the present material displays a noticeable higher resistance to fatigue crack growth, especially in the near-threshold regime. The $R$-ratio dependency of the threshold $\Delta K_{\text {th }}$ is well represented by the Walker equation [59]:

$$
\Delta K_{\text {th }}=\overline{\Delta K}_{\text {th }}(1-R)^{1-\gamma_{\text {th }}}
$$

as shown in Figure 7b, where the least-square fit of Equation (4) is compared for both material types. Unfortunately, no information is provided in [54] about the size of the cracks monitored in the fatigue crack growth experiments. Therefore, the comparison of the results shown in Figure 7a,b could be impaired by different levels of deployment of the crack retardation mechanisms. Nevertheless, it seems that the presence of degenerated graphite has a beneficial, or at least non-detrimental, effect on the material fatigue crack growth resistance. This unexpected result can be explained looking at Figure 8a, which depicts a SEM overview of the fatigue facture surface in the vicinity of the near-threshold propagation region. The fracture surface is characterized by the presence of different graphite morphologies, ranging from nearly spherical nodules to fine dispersion of chunky graphite. Notably, the regions containing no graphite at all or surrounding graphite spheroids show large evidence of brittle cleavage (see the river pattern indicated by an arrow in Figure 8b) and intergranular fracture, as shown in more detail in Figure 8b,c, respectively. On the contrary, the presence of chunky graphite is associated to a less brittle fracture mode resulting in rougher fracture surface. Similar 
indications are given by crack front profiles taken from regions under the same crack propagation regime and shown in Figure 9. Indeed, it can be noticed that where the crack front encounters regions characterized by degenerated graphite (Figure 9a) the crack profile is significantly rougher than where spherical graphite nodules only are present (Figure $9 b$ ). The former scenario will result in more effective crack retardation mechanisms, such as roughness-induced crack closure [53] and crack front geometry effects [54], with respect to the latter one representative of conditions occurring in conventional DCI.

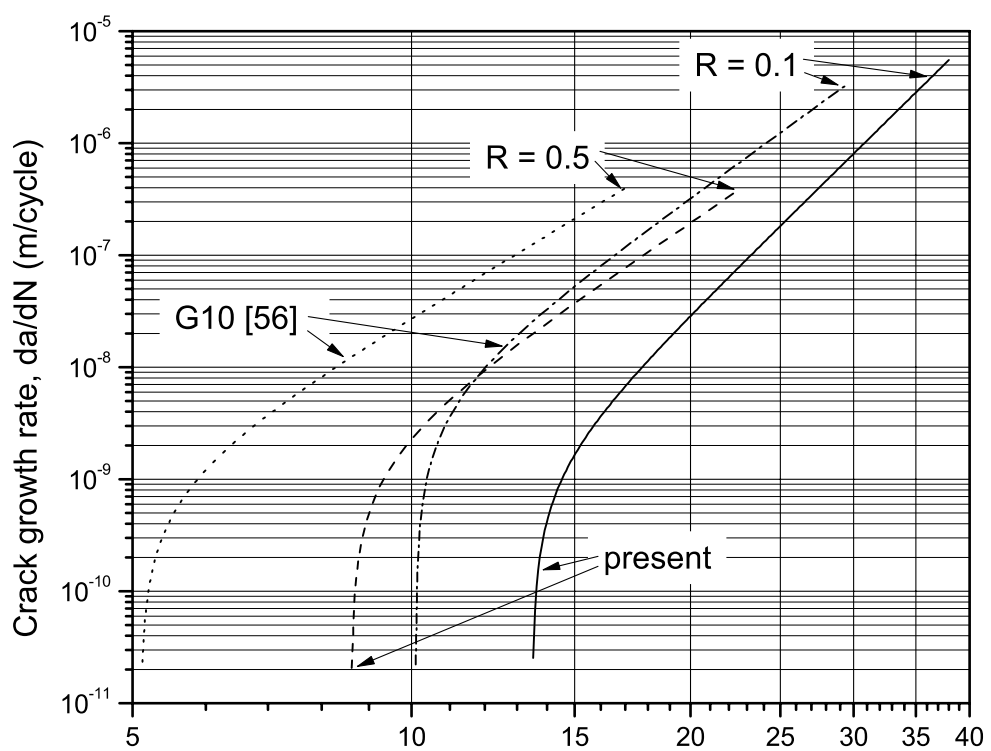

(a)

Stress intensity factor range, $\Delta \mathrm{K}\left(\mathrm{MPa} \mathrm{m}^{0.5}\right)$

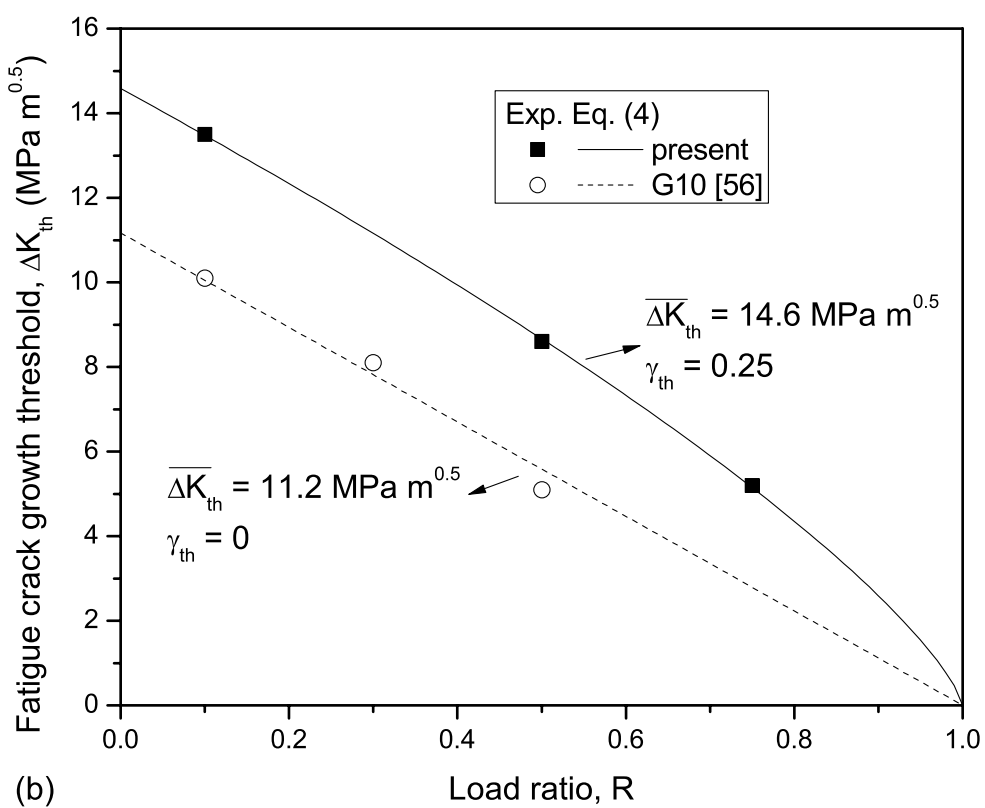

Figure 7. Comparison of fatigue crack growth resistance with data [54] referring to a similar ductile cast iron (DCI) subject to normal solidification conditions: (a) $\mathrm{d} a / \mathrm{d} N-\Delta K$ curves; and (b) threshold dependency upon load ratio $R$. 


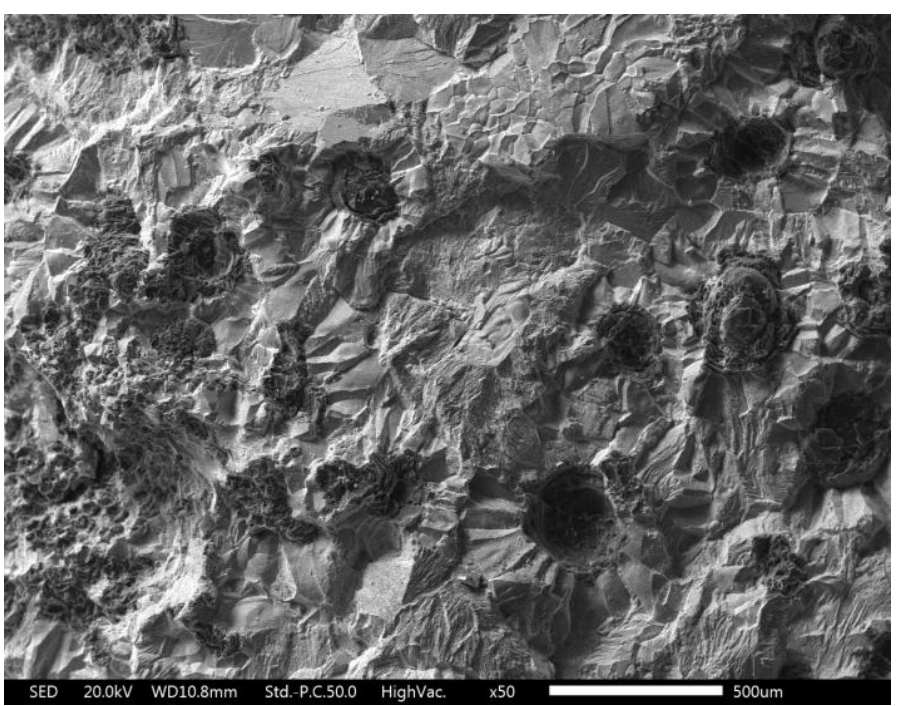

(a)

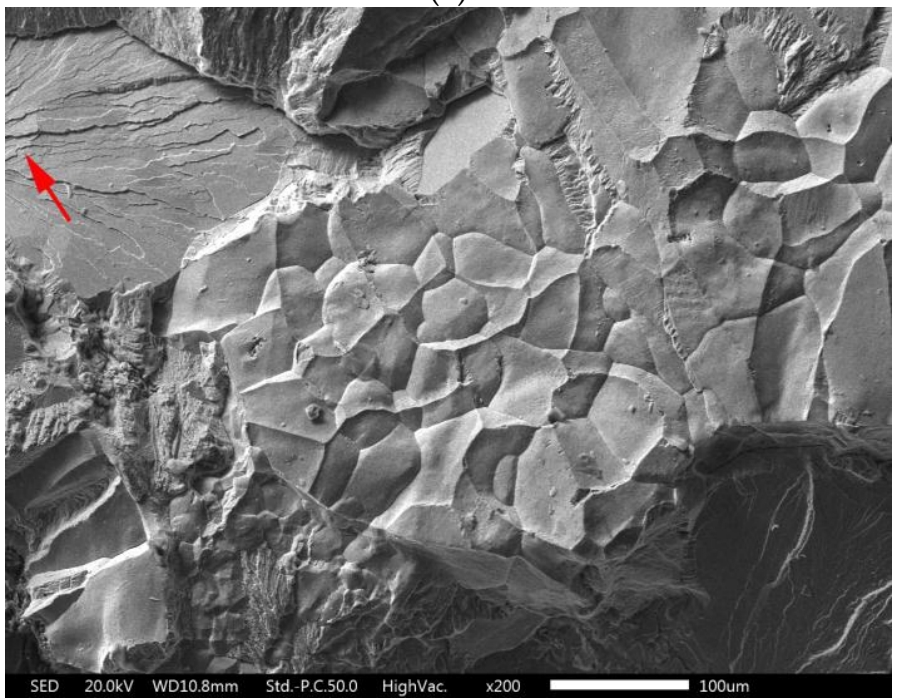

(b)

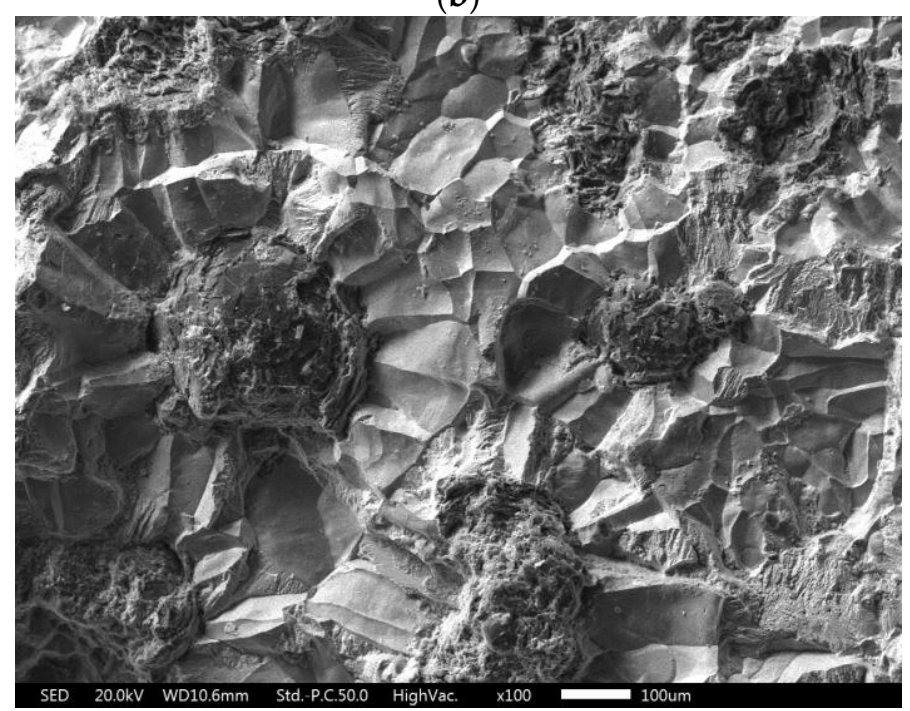

(c)

Figure 8. scanning electron microscope (SEM) micrographs of the fatigue fracture surfaces of the $C(T)$ sample tested at $R=0.1$ : (a) overview of the near-threshold crack propagation region; (b) detail of cleavage (marked by an arrow) and intergranular fracture; and (c) detail of a graphite spheroidal nodule. Crack propagation from top to bottom. 


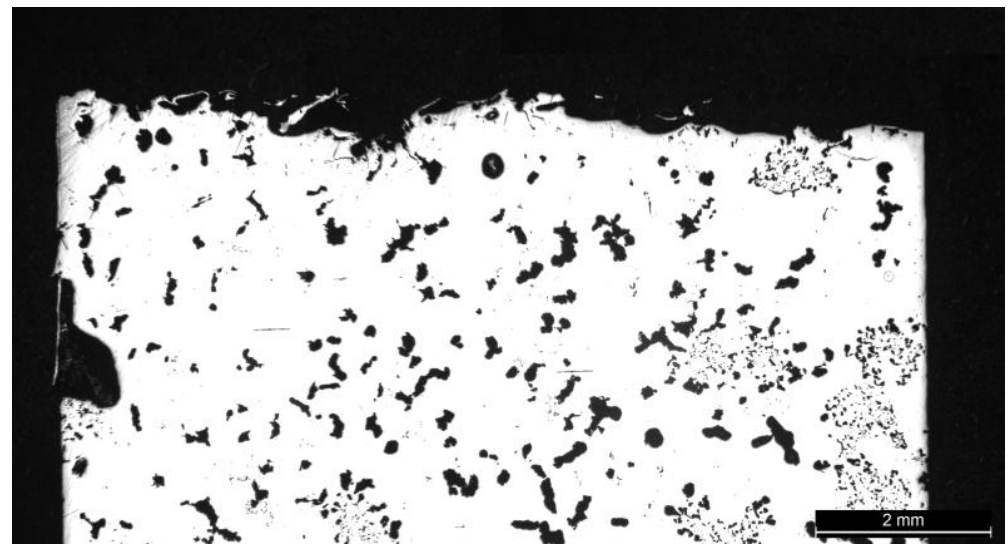

(a)

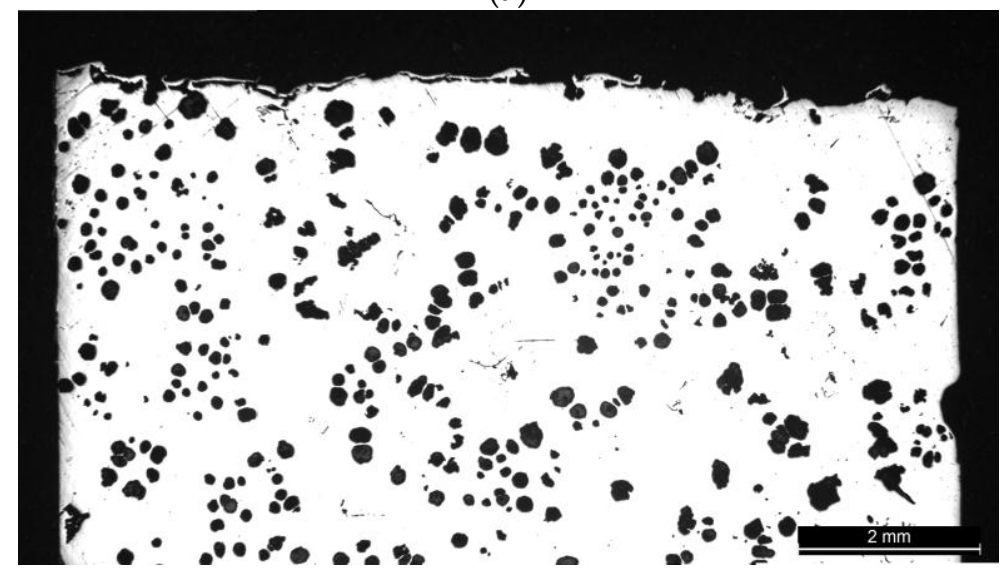

(b)

Figure 9. Light microscope images of crack front profiles taken in the near-threshold crack propagation region: (a) cross-section with significant presence of chunky graphite; and (b) cross-section with prevailing nodular graphite. Crack path direction is normal to paper plane.

\subsection{Fracture Toughness}

$K_{I c}$ fracture toughness tests are performed on $\mathrm{C}(\mathrm{T})$ specimens depicted in Figure 2c, whose geometry is taken as large as possible with the aim of satisfying the linear elastic fracture mechanics requirement expressed by [60]:

$$
B, a, W-a>2.5\left(\frac{K_{I c}}{\sigma_{Y S}}\right)^{2}
$$

where $a, B$ and $W$ are the initial crack length, specimen thickness and width, respectively. Considering the value of the material yield strength $\sigma_{Y S}$ listed in Table 3, the maximum theoretical fracture toughness that can be estimated using this $\mathrm{C}(\mathrm{T})$ sample geometry is $\approx 32 \mathrm{MPa} \mathrm{m}^{0.5}$, which is comparable with $K_{\text {Ic }}$ values reported in the technical literature $[56,57]$ for this DCI class.

Figure 10a,b shows the load versus crack mouth opening displacement recorded for specimen 1 and 2, respectively. In both cases, the record is of Type I according to ASTM-1820, in the sense that the load $P_{Q}$ is determined as the intersection of the force versus crack opening displacement record with the $95 \%$ secant. Unexpectedly, despite the use of thick-walled and side-grooved specimens, the requirement on the ratio maximum load $P_{\max }$ to $P_{Q}$ to be $\leq 1.10$, which is necessary for $K_{Q}$ to be qualified as linear elastic, plane-strain fracture toughness $K_{I c}$, is not met. Therefore, the present tests result in thickness-dependent fracture toughness values, which can be used to safely design only components with thickness not larger than $32 \mathrm{~mm}$. Apparently, the highly nonlinear stress-strain 
behavior displayed by cast irons makes very difficult to meet the ASTM-1820 requirement on $P_{Q}$, even though the conditions set by Equation (5) are fulfilled.
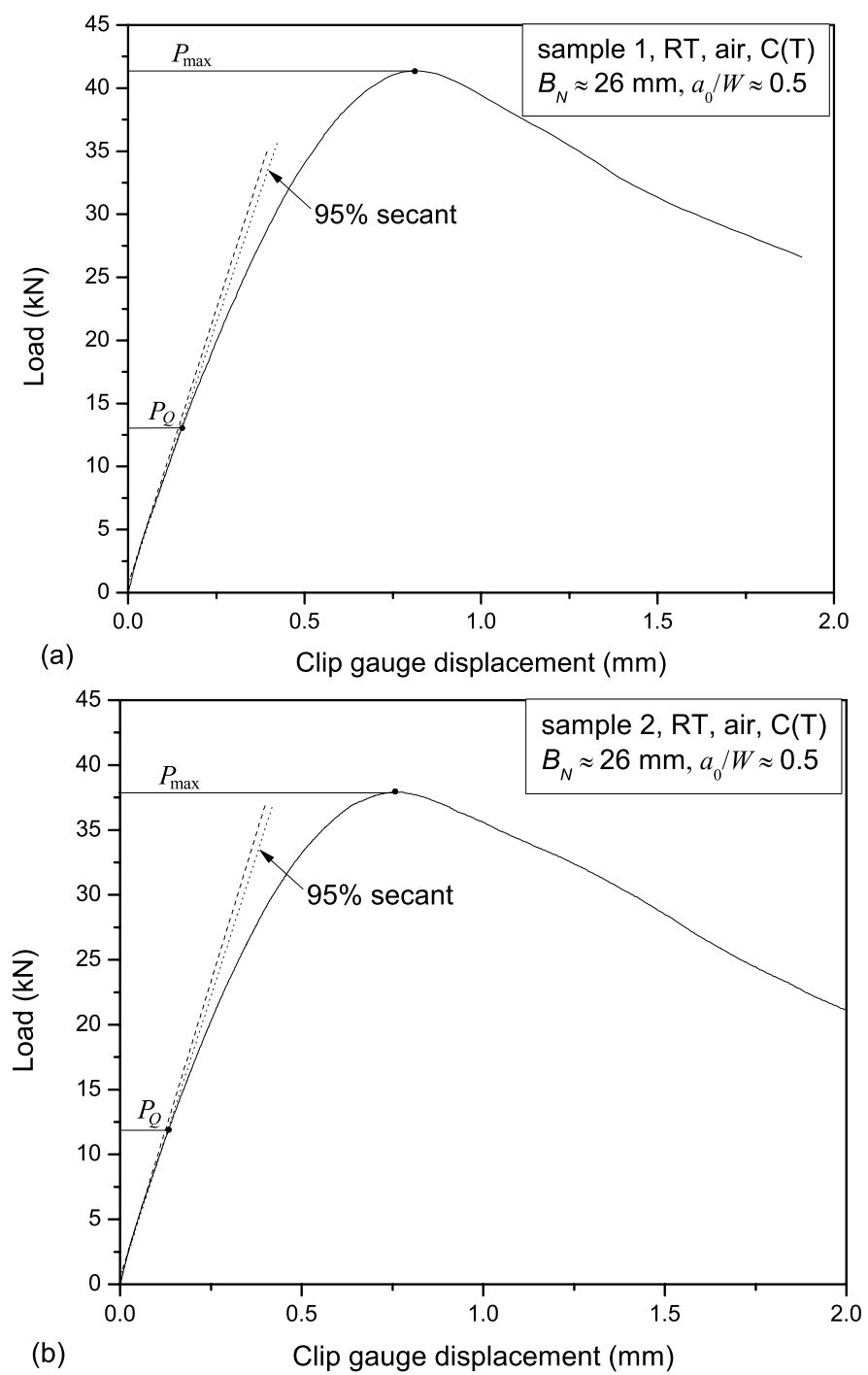

Figure 10. Load versus crack mouth opening displacement recorded for: specimen 1 (a); and specimen 2 (b) used in fracture toughness testing.

Table 6 summarizes the results of the two fracture toughness tests and compares them with data found in the technical literature regarding similar EN-GJS-400 DCI subjected to normal solidification conditions. The average fracture toughness $K_{Q}$ is $17.3 \mathrm{MPa} \mathrm{m}^{0.5}$, which is $14 \%$ lower than the value reported by Zambrano et al. [55]. It must be noted that this latter value was obtained using samples with thickness of only $10 \mathrm{~mm}$, therefore at least part of the observed reduction in fracture toughness could be induced to a higher triaxility of the crack tip stress field experienced by the samples tested in the present work. On the other hand, unfavorable microstructural conditions caused by the long solidification time could have a negative effect on the fracture toughness, even though to a lesser extent than that observed in Section 3.2 on tensile and fatigue strength. 
Table 6. Results of the fracture toughness tests and comparison with literature data.

\begin{tabular}{|c|c|c|c|c|}
\hline Specimen & Thickness, $B$ (mm) & $K_{Q}\left(\mathrm{MPa} \mathrm{m}^{0.5}\right)$ & $K_{\operatorname{Pmax}}\left(\mathrm{MPa} \mathrm{m}^{0.5}\right)$ & $K_{\mathrm{Ic}} *\left(\mathrm{MPa} \mathrm{m}{ }^{0.5}\right)$ \\
\hline 1 & 32 & 18.0 & 57.3 & - \\
\hline 2 & 32 & 16.6 & 50.2 & - \\
\hline $\mathrm{C}(\mathrm{T})[55]$ & 10 & 20 & 39 & - \\
\hline WK1 [47] & 10 & - & - & 32 \\
\hline G10 [56] & 10 & - & - & 33.2 \\
\hline
\end{tabular}

* Data inferred from fatigue crack growth rate vs. $\Delta K$ curves.

Hübner et al. [47] and Mottitschka et al. [56] did not perform true fracture mechanics tests but inferred the material fracture toughness $K_{\text {Ic }}$ from fatigue crack growth tests and calculated it as $K_{\mathrm{Ic}}=\Delta K_{\mathrm{c}} /(1-R)$, where $\Delta K_{\mathrm{c}}$ is the asymptotic value of the stress intensity range at which the crack growth rate tends to infinite. Clearly, this is not a true stress intensity factor, as prescriptions and procedures set by ASTM-1820 are not met. Anyway, if the data illustrated in Figure 6 are elaborated in the same way, a value of $K_{\mathrm{Ic}} \approx 45 \mathrm{MPa} \mathrm{m}{ }^{0.5}$ is obtained, thus higher than the values reported by $[47,56]$.

\section{Conclusions}

Solidification conditions typical of heavy-section castings were reproduced on a small-scale ductile cast iron (DCI) casting, from which laboratory coupons were extracted and used to carry out monotonic tensile, fatigue and fracture mechanics tests. The obtained results were discussed by comparison with data available in the technical literature. The following conclusions can be drawn:

(1) The microstructure consists of a prevailing ferritic matrix, in which $2 / 3$ of graphite is interspersed in form of overgrown spheroidal nodules and the rest in form of chunky graphite.

(2) The tensile strength and the total elongation are reduced by $20 \%$ and $75 \%$ with respect to thick-walled ( $t>60 \mathrm{~mm}$ ) EN-GJS-400-15.

(3) The rotating bending fatigue limit at five million cycles is reduced by $30 \%$ with respect to the standard EN-1563 reporting the results of fatigue tests employing laboratory samples extracted from thin-walled castings. The fatigue limit is strongly correlated to the dimension of the largest shrinkage pore found on the fracture surface. Nevertheless, shrinkage pores are not the only defects involved in the fatigue damage, as also degenerated chunky graphite can be site of crack nucleation.

(4) The material displays a higher fatigue crack growth resistance, especially in the near-threshold regime, with respect to DCI subject to normal solidification conditions. This has been attributed, at least partially, to crack front geometry effects and crack closure phenomena induced by the high roughness and interlocking crack mating surfaces in the neighborhood of chunky graphite.

(5) The fracture toughness is $14 \%$ lower than that reported for DCI obtained under normal solidification conditions. On the other hand, the thickness of the samples used in the present experimentation is three times larger than that of specimens usually tested in the literature. The highly nonlinear stress-strain behavior displayed by cast irons makes very difficult to meet the ASTM prescription on the $P_{Q}$ load.

Author Contributions: D.L. prepared the samples and performed static tensile and rotating bending fatigue tests. E.T. conducted metallographic and fractographic analyses. V.F. contributed to the analysis and discussion of the results. M.B. carried out the fracture mechanics tests, contributed to the analysis and discussion of the results and wrote the paper.

Conflicts of Interest: The authors declare no conflict of interest. 


\section{References}

1. Luo, J.; Hardning, R.A.; Bowen, P. Evaluation of the fatigue behavior of ductile irons with various matrix microstructures. Metall. Mater. Trans. A 2002, 33A, 3719-3729. [CrossRef]

2. Di Cocco, V.; Iacoviello, F.; Rossi, A.; Cavallini, M.; Natali, S. Graphite nodules and fatigue crack propagation micromechanisms in a ferritic ductile cast iron. Fatigue Fract. Eng. Mater. Struct. 2013, 36, 893-902. [CrossRef]

3. Kaufmann, H.; Wolters, D.B. Zyklische Beanspruchbarkeit dickwandiger Bauteile aus ferritischem Gusseisen mit Kugelgraphit. Konstr. Giess. 2002, 27, 4-27.

4. Minnebo, P.; Nilsson, KF.; Blagoeva, D. Tensile, compression and fracture properties of thick walled ductile cast iron components. J. Mater. Eng. Perform. 2007, 16, 35-45. [CrossRef]

5. Kobayashi, M.; Yamabe, J. Influence of casting surfaces on fatigue strength of ductile cast iron. Fatigue Fract. Eng. Mater. Struct. 2006, 29, 403-415.

6. Meneghetti, G.; Ricotta, M.; Masaggia, S.; Atzori, B. Comparison of the los cycle and medium cycle fatigue behaviour of ferrtic, pearlitic, isothermed and austempered ductile irons. Fatigue Fract. Eng. Mater. Struct. 2013, 36, 913-929. [CrossRef]

7. Wang, Q.Y.; Bathias, C. Fatigue characterization of a spheroidal graphite cast iron under ultrasonic loading. J. Mater. Sci. 2004, 39, 687-689. [CrossRef]

8. Caldera, M.; Chapetti, M.; Massone, J.M.; Sikore, J.A. Influence of nodule count on fatigue properties of ferritic thin wall ductile iron. Mater. Sci. Technol. 2007, 23, 1000-1004. [CrossRef]

9. Andreiko, I.M.; Ostash, O.P.; Popovych, V.V. Influence of microstructure on the strength and cyclic crack resistance of cast irons. Mater. Sci. 2002, 38, 659-671. [CrossRef]

10. Greno, G.L.; Otegui, J.L.; Boeri, R.E. Mechanisms of fatigue crack growth in austempered ductile Iron. Int. J. Fatigue 1999, 21, 35-43. [CrossRef]

11. Borsato, T.; Ferro, P.; Berto, F.; Carollo, C. Mechanical and fatigue properties of heavy section solution strengthened ferritic ductile iron castings. Adv. Eng. Mater. 2016, 18, 2070-2075. [CrossRef]

12. Borsato, T.; Ferro, P.; Berto, F.; Carollo, C. Fatigue strength improvement of heavy-section pearlitic ductile iron castings by in-mould inoculation treatment. Int. J. Fatigue 2017. [CrossRef]

13. Taylor, D.; Hughes, M.; Allen, D. Notch fatigue behavior in cast irons explained using a fracture mechanics approach. Int. J. Fatigue 1996, 18, 439-445. [CrossRef]

14. Davis, J.R. Cast Irons, 1st ed.; ASM International: Materials Park, OH, USA, 1996; p. 65.

15. Karsay, S.I. Control of Graphite Structure in Heavy Ductile Iron Castings. AFS Trans. 1970, 78, 85-92.

16. Strizik, P.; Jeglitsch, F. Contribution to the Mechanism of Formation of Chunky Graphite. AFS Int. Cast Met. J. 1976, 1, 23-30.

17. Liu, P.C.; Li, C.L.; Wu, D.H.; Loper, C.R. SEM Study of Chunky Graphite in Heavy Section Ductile Iron. AFS Trans. 1983, 91, 119-126.

18. Hoover, H.W., Jr. A literature survey on degenerate graphite in heavy section ductile iron. Trans. Am. Foundrym. Soc. 1986, 94, 601-608.

19. Stefanescu, D.M.; Alonso, G.; Larrañaga, P.; De la Fuente, E.; Suarez, R. On the crystallization of graphite from liquid iron-carbon-silicon melts. Acta Mater. 2016, 107, 102-126. [CrossRef]

20. Itofuji, H.; Uchikawa, H. Formation mechanism of chunky graphite in heavy-section ductile cast irons. AFS Trans. 1990, 90, 429-448.

21. Gagné, M.; Argo, D. Heavy section ductile cast iron castings part I and part II. In Proceedings of the an International Conference on Advanced Casting Technology, Kalamazoo, MI, USA, 12-14 November 1989; ASM International: Materials Park, OH, USA, 1989; pp. 231-256.

22. Nakae, H.; Junk, S.; Shin, H.-C. Formation mechanism of chunky graphite and its preventive measures. J. Mater. Sci. Technol. 2008, 24, 289-295.

23. Udroiu, A. Wedge theory: new approach to explain the formation of "chunky graphite" in ductile iron. In Proceeding of the 70th World Foundry Congress, Monterrey, Mexico, 25-27 April 2012; pp. 614-631.

24. Källbom, R.; Hamberg, K.; Wessén, M.; Björkegren, L.-E. On the solidification sequence of ductile iron castings containing chunky graphite. Mater. Sci. Eng. A 2005, 413-414, 346-351. [CrossRef]

25. Riposan, I.; Chisamera, M.; Stan, A. Control surface graphite degeneration ductile iron windmill applications. Int. J. Metalcast. 2013, 7, 9-20. [CrossRef] 
26. Nakae, H.; Fukami, M.; Kitazawa, T.; Zou, Y. Influence of Si, Ce, Sb and Sn on chunky graphite formation. China Foundry 2011, 8, 96-100.

27. Lacaze, J.; Armendariz, S.; Larrañaga, P.; Asenjo, I.; Sertucha, J.; Suarez, R. Effect of carbon equivalent on graphite formation in heavy-section ductile iron parts. Mater. Sci. Forum 2010, 636-637, 523-530. [CrossRef]

28. Riposan, I.; Chisamera, M.; Uta, V.; Stan, S. The importance of rare earth contribution from nodulizing alloys and their subsequent effect on the inoculation of ductile iron. Int. J. Metalcast. 2014, 8, 65-80. [CrossRef]

29. Onsøien, M.I.; Grong, Ø.; Skaland, T.; Jørgensen, K. Mechanisms of graphite formation in ductile cast iron containing rare earth metals. Mater. Sci. Technol. 1999, 15, 253-259. [CrossRef]

30. Choi, J.O.; Kim, J.Y.; Choi, C.O.; Kim, J.K.; Rohatgi, P.K. Effect of rare earth element on microstructure formation and mechanical properties of thin wall ductile iron castings. Mater. Sci. Eng. A 2004, 383, 323-333. [CrossRef]

31. Zhe, L.; Weiping, C.; Yu, D. Influence of cooling rate and antimony addition content on graphite morphology and mechanical properties of a ductile iron. China Foundry 2012, 9, 114-118.

32. Diao, X.G.; Ning, Z.L.; Cao, F.Y.; Ren, S.Z.; Sun, J.F. Effects of antimony addition and section size on formation of chunky graphite in ductile iron. Mater. Sci. Technol. 2011, 27, 834-838. [CrossRef]

33. Gorny, M.; Tyrala, E. Effect of cooling rate on microstructure and mechanical properties of thin-walled ductile iron castings. J. Mater. Eng. Perform. 2013, 22, 300-305. [CrossRef]

34. Ferro, P.; Fabrizi, A.; Cervo, R.; Carollo, C. Effect of inoculant containing rare earth metals and bismuth on microstructure and mechanical properties of heavy-section near-eutectic ductile iron castings. J. Mater. Process. Technol. 2013, 213, 1601-1608. [CrossRef]

35. Zhang, Z.; Flower, H.M.; Niu, Y. Classification of degenerate graphite and its formation processes in heavy section ductile iron. Mater. Sci. Technol. 1989, 5, 657-664. [CrossRef]

36. Skaland, T.; Grong, Ø.; Grong, T. A model for the graphite formation in ductile cast iron. Metall. Mater. Trans. A 1993, 24A, 2321-2345. [CrossRef]

37. Asenjo, I.; Larrañaga, P.; Sertucha, J.; Suárez, R.; Gómez, J.-M.; Ferrer, I.; Lacaze, J. Effect of mould inoculation on formation of chunky graphite in heavy section spheroidal graphite cast iron parts. Int. J. Cast Met. Res. 2007, 20, 319-324. [CrossRef]

38. Kallbom, R.; Hamberg, K.; Björkegren, L.-E. Chunky graphite-Formation and influence on mechanical properties in ductile cast iron. In Competent Design by Castings_-Improvements in a Nordic Project; Samuelson, J., Marquis, G., Solin, J., Eds.; VTT: Helsinki, Finland, 2005; pp. 63-86.

39. Endo, M.; Yanase, K. Effects of small defects, matrix structures and loading conditions on the fatigue strength of ductile cast irons. Theor. Appl. Fract. Mech. 2014, 69, 34-43. [CrossRef]

40. Mourujärvi, A.; Widell, K.; Saukkonen, T.; Hänninen, H. Influence of chunky graphite on mechanical and fatigue properties of heavy-section cast iron. Fatigue Fract. Eng. Mater. Struct. 2009, 32, 379-390. [CrossRef]

41. Ferro, P.; Lazzarin, P.; Berto, F. Fatigue properties of ductile cast iron containing chunky graphite. Mater. Sci. Eng. A 2012, 554, 122-128. [CrossRef]

42. Foglio, E.; Lusuardi, D.; Pola, A.; La Vecchia, G.M.; Gelfi, M. Fatigue design of heavy section ductile irons: Influence of chunky graphite. Mater. Des. 2016, 111, 353-361. [CrossRef]

43. Nadot, Y.; Mendez, J.; Ranganathan, N.; Beranger, A.S. Fatigue life assessment of nodular cast iron containing casting defects. Fatigue Fract. Eng. Mater. Struct. 1999, 22, 289-300. [CrossRef]

44. Collini, L.; Pirondi, A. Fatigue crack growth analysis in porous ductile cast iron microstructure. Int. J. Fatigue 2014, 62, 258-265. [CrossRef]

45. Collini, L.; Pirondi, A.; Bianchi, R.; Cova, M.; Milella, P.P. Influence of casting defects on fatigue crack initiation and fatigue limit of ductile cast iron. Procedia Eng. 2011, 10, 2898-2903. [CrossRef]

46. Murakami, Y. Metal Fatigue: Effects of Small Defects and Nonmetallic Inclusions, 1st ed.; Elsevier: Oxford, UK, 2002.

47. Hübner, P.; Schlosser, H.; Pusch, G.; Biermann, H. Load history effects in ductile cast iron for wind turbine components. Int. J. Fatigue 2007, 29, 1788-1796. [CrossRef]

48. Benedetti, M.; Fontanari, V.; Zonta, D. Structural health monitoring of wind towers: Remote damage detection using strain sensors. Smart Mater. Struct. 2011, 20, 055009. [CrossRef]

49. Benedetti, M.; Fontanari, V.; Battisti, L. Structural health monitoring of wind towers: Residual fatigue life estimation. Smart Mater. Struct. 2013, 22, 045017. [CrossRef] 
50. Foglio, E.; Gelfi, M.; Pola, A.; Goffelli, S.; Lusuardi, D. Fatigue Characterization and Optimization of the Production Process of Heavy Section Ductile Iron Castings. Int. J. Metalcast. 2017, 11, 33-43. [CrossRef]

51. European Standard EN 1563:2011. Founding—Spheroidal Graphite Cast Iron; CEN: Brussels, Belgium, 2011.

52. Murakami, Y.; Endo, M. Effects of hardness and crack geometries on $\Delta \mathrm{K}_{\mathrm{th}}$ of small cracks emanating from small defects. In The Behaviour of Short Fatigue Cracks; Miller, K.J., de los Rios, E.R., Eds.; Institution of Mechanical Engineers: London, UK, 1986; pp. 275-293.

53. Ritchie, R.O. Mechanisms of fatigue-crack propagation in ductile and brittle solids. Int. J. Fract. 1999, 100, 55-83. [CrossRef]

54. Benedetti, M.; Heidemann, J.; Peters, J.O.; Lütjering, G. Influence of sharp microstructural gradients on the fatigue crack growth resistance of $\alpha+\beta$ and near- $\alpha$ titanium alloys. Fatigue Fract. Eng. Mater. Struct. 2005, 28, 909-922. [CrossRef]

55. Zambrano, H.R.; Härkegård, G.; Stärk, K.F. Fracture toughness and growth of short and long fatigue cracks in ductile cast iron EN-GJS-400-18-LT. Fatigue Fract. Eng. Mater. Struct. 2011, 35, 374-388. [CrossRef]

56. Mottitschka, T.; Pusch, G.; Biermann, H.; Zybell, L.; Kuna, M. Influence of overloads on the fatigue crack growth in nodular cast iron: Experiments and numerical simulation. Procedia Eng. 2010, 2, 1557-1567. [CrossRef]

57. Čanžar, P.; Tonković, Z.; Kodvanj, J. Microstructure influence on fatigue behaviour of nodular cast iron. Mater. Sci. Eng. A 2012, 556, 88-99. [CrossRef]

58. Klesnil, M.; Lukáš, P. Influence of strength and stress history on growth and stabilisation of fatigue cracks. Eng. Fract. Mech. 1972, 4, 77-92. [CrossRef]

59. Walker, E.K. The effect of stress ratio during crack propagation and fatigue for 2024-T3 and 7075-T6 aluminum. In Effect of Environment and Complex Load History on Fatigue Life; American Society for Testing and Materials: West Conshohocken, PA, USA, 1970; pp. 1-14.

60. Anderson, T.L. Fracture Mechanics: Fundamentals and Applications, 3rd ed.; CRC Press: Boca Raton, FL, USA, 2005.

(C) 2017 by the authors. Licensee MDPI, Basel, Switzerland. This article is an open access article distributed under the terms and conditions of the Creative Commons Attribution (CC BY) license (http:/ / creativecommons.org/licenses/by/4.0/). 